OPEN ACCESS

Edited by:

Lingling Wang,

Dalian Ocean University, China

Reviewed by:

Hon Jung Liew,

University of Malaysia Terengganu,

Malaysia

Rachel Michelle Wright

Harvard Medical School,

United States

*Correspondence:

Xiubao $\mathrm{Li}$

xiubaoli@hainanu.edu.cn

Specialty section:

This article was submitted to

Aquatic Physiology,

a section of the journal

Frontiers in Marine Science

Received: 16 April 2021

Accepted: 19 August 2021

Published: 08 September 2021

Citation:

Zhang Y, Huang J, Li X, Song C,

Xia J, Ren Y, Wang A and Li X (2021)

Improper Diving Behavior Affects

Physiological Responses of Acropora

hyacinthus and Porites cylindrica.

Front. Mar. Sci. 8:696298.

doi: 10.3389/fmars.2021.696298

\section{Improper Diving Behavior Affects Physiological Responses of Acropora hyacinthus and Porites cylindrica}

\author{
Yu Zhang ${ }^{1}$, Jianzhong Huang ${ }^{2}$, Xinke Li', Cuiping Song ${ }^{1}$, Jingquan Xia ${ }^{1}$, Yuxiao Ren ${ }^{1}$, \\ Aimin Wang ${ }^{1,3}$ and Xiubao $\mathrm{Li}^{1,3 *}$ \\ ' College of Marine Science, Hainan University, Haikou, China, ${ }^{2}$ College of Ecology and Environment, Hainan University, \\ Haikou, China, ${ }^{3}$ State Key Laboratory of Marine Resource Utilization in South China Sea, Hainan University, Haikou, China
}

Human activities beyond ecosystem capacity have resulted in serious effects on corals worldwide. Nowadays, many studies have focused on the influence of diving activities on coral communities, while the knowledge of physiological changes under corresponding environmental stresses remains largely undetermined. In the study, we aimed to investigate the physiological effects of touching, ammonia nitrogen enrichment (5 $\mathrm{mmol} \cdot \mathrm{L}^{-1}$ ), and sediment cover (particle size of less than $0.3 \mathrm{~mm}$ ), which simulated improper self-contained underwater breathing apparatus (SCUBA) diving behaviors, on Acropora hyacinthus and Porites cylindrica in Wuzhizhou Island, the South China Sea. For $A$. hyacinthus, continuous touching caused the tentacles to shrink and secrete mucus, which consumed energy and dissolved oxygen. The skeletal growth rate was decreased by $72 \%$ compared with the control group. There was a rapid decline of $\mathrm{Fv} / \mathrm{Fm}$ and alpha under the dual impacts of high ammonia nitrogen and touching, while the Chl a concentration and tissue biomass were decreased by 36 and $28 \%$ compared with touching alone, respectively. High ammonia nitrogen and touching increased the concentrations of lipid and protein. Nevertheless, zooxanthellae density was increased by $23 \%$ to relieve the effects of a lower concentration of $\mathrm{Chl}$ a in a high nutrient environment. Constant touching and sediment cover in diving areas with elevated ammonia content affected the photosynthesis and respiration of corals, and a significant decrease was observed for lipid, zooxanthellae density, and Chl a concentration. Coral bleaching occurred on day 7. For P. cylindrica, the decreasing magnitude of Fv/Fm and alpha under different stresses in the subsequent phase was less compared with A. hyacinthus. The contents of carbohydrate and protein under continuous touching were decreased by 7 and 15\% compared with the control group, respectively, causing negative growth. Under the dual influences of high ammonia nitrogen and continuous touching, all energy reserves were significantly lower. Repeated touching and sediment cover in diving areas containing high ammonia content increased the concentrations of lipid and protein compared with the touching and high nutrient treatment group likely because that Porites associated with C15 zooxanthella increased heterotrophic feeding to compensate for restricted symbiodiniaceae photosynthesis. Additionally, P. cylindrica produced mucus to aid the removal of sediment, so that corals didn't obviously bleach 
during the experiment. Collectively, $P$. cylindrica was more resistant to diving activities than $A$. hyacinthus which only relies on photoautotrophy. To ensure the sustainable development of coral reef dive tourism, it is necessary to strengthen the supervision of diving behaviors, rotate the diving areas, and conduct regular assessments on the coral status.

Keywords: human activities, SCUBA diving, Acropora hyacinthus, Porites cylindrica, environmental stress, physiological parameters

\section{INTRODUCTION}

During the past decade, coral reef ecosystems have seriously degraded worldwide due to the mighty pressure of human activities and natural stresses (Guest et al., 2016). The coverage of fringing reefs off its coast in Hainan Island has been decreased by at least $80 \%$ since the last century, and such reduction is mainly attributed to human activities, such as overfishing, aquaculture, coastal engineering, and tourism (Li et al., 2012; Hughes et al., 2013; Huang et al., 2020). As one of the fastest-growing and most prevalent tourism projects worldwide (Ong and Musa, 2011), diving tourism has been considered as a sustainable pattern for coral reef use compared with coral harvesting and fishing for commercial purposes (Dearden et al., 2007). Nevertheless, diving activities exceeding ecosystem capacity have exerted profound negative effects on coral reefs (Zakai and Chadwick-Furman, 2002; Lamb et al., 2014). The coverage and biological diversity of coral reefs have been sharply decreased at high-intensity diving sites, such as the Caribbean Sea, the Red Sea, Great Barrier Reef, the west coast of India, and Redang and Payar (Malaysia), leading to a large number of dead corals and coral rubbles (Crehan et al., 2019; De et al., 2020). Over $50 \%$ of the coral communities in the diving areas in the Red Sea, especially in Eilat, have bleached (Jameson et al., 1999; Zakai and Chadwick-Furman, 2002). More than $80 \%$ of coral communities in Florida have been damaged, and the coverage of live corals has been reduced below $11 \%$ at high-intensity diving sites (Krieger and Chadwick, 2013).

Improper diving behaviors, such as touching, standing, kneeling, and walking on corals, snagging by equipment, and kicking corals with their fins (Abidin and Mohamed, 2014), can cause coral tissue damage, making them extremely sensitive to changes in water temperature and nitrogen content and hardly recover from stresses, such as undersea storms and bleaching (Carilli et al., 2010). Intensive diving activities also increase the prevalence of coral diseases (Lamb et al., 2014). The direct damage to corals and the resuspension of sediment due to diving may not have significant effects on corals, while their combinations with other stresses, such as increased nutrient levels, may weaken corals' resistance to microbial infestation or indirectly increase pathogen toxicity (Nystrm et al., 2000; Altizer et al., 2013). Lamb et al. (2014) has found that the health rates of corals (79\%) are much higher at low-intensity diving sites compared with high-intensity diving sites $(45 \%)$ in Koh Tao, Thailand. The incidence of coral diseases, including skeletal eroding band, white syndrome, and black band, in high-intensity diving sites, is significantly higher compared with low-intensity diving sites. Many studies have shown that branching corals are more susceptible to diver's damage than massive corals due to their fragile structure (Mastny, 2001; Barker and Roberts, 2004) and weak resistance to experimental pressure (Rouphael and Inglis, 2002), except for branching corals in Porites (Krieger and Chadwick, 2013). On the contrary, massive corals, such as many species in Porites, have stronger resistance to external pressures (Au et al., 2014; Crehan et al., 2019). Therefore, the susceptibility of different coral species to intensive recreational diving and repeated coral injury depends on community structures and local ecological conditions (Abidin and Mohamed, 2014).

The Wuzhizhou (WZZ) Island, located on the southeastern coast of the Hainan Island in the South China Sea, is a popular dive resort in China. WZZ has received about 3 million tourists in 2017, of which about $10 \%$ participate in the diving projects (Huang et al., 2020). Due to the rapid development of self-contained underwater breathing apparatus (SCUBA) diving, underwater sightseeing, and other recreational activities, turbidity and nutrient content [such as the dissolved inorganic nitrogen (DIN) and $\mathrm{NH}_{4}{ }^{+}$] of northern WZZ are much higher compared with the south. In 2017, the turbidity in the north of WZZ island is $0.41 \mathrm{FTU}$, and the contents of DIN and $\mathrm{NH}_{4}{ }^{+}$are $3.37 \mu \mathrm{mol} \cdot \mathrm{L}^{-1}$ and $2.61 \mu \mathrm{mol} \cdot \mathrm{L}^{-1}$, respectively. In contrast, the turbidity in the south is $0.28 \mathrm{FTU}$, and the contents of DIN and $\mathrm{NH}_{4}{ }^{+}$are 2.88 and $2.1 \mu \mathrm{mol} \cdot \mathrm{L}^{-1}$, respectively. Meanwhile, the coverage of live corals in the north is decreased from $79.9 \%$ in 2007 to $30.2 \%$ caused by intensive construction, land-use change, and tourism development in 2016 (Huang et al., 2020). The studies on the impact of human activities are mostly based on field investigation. However, we cannot accurately understand the impacts of human activities, such as recreational diving, on coral reefs by analyzing macro-ecological indicators, such as live coral coverage, species diversity, and dominant species (Dinsdale and Harriott, 2004).

Combined with previous studies and our observations in diving areas, SCUBA diving activities affect coral growth mainly from the following three aspects. First, SCUBA divers affect the stony corals both intentionally and unintentionally through physical contact with their hands, bodies, equipment, and fins (Zakai and Chadwick-Furman, 2002; Uyarra and $\mathrm{Co}^{\wedge} \mathrm{te}^{\prime}$, 2007). The research has shown that Florida divers contact live corals 18 times every $60 \mathrm{~min}$, including 12 times with fins, three times with hands, and two times with diving equipment (Krieger and Chadwick, 2013). Second, some diving tourists urinate in coral reef areas. Water quality may affect coral health (Reopanichkul et al., 2009). Third, when divers swim too close 
to corals, they may inadvertently stir up the benthic sediment, leading to increased sediment loads to coral polyps (Zakai and Chadwick-Furman, 2002; Wielgus et al., 2004), and resulting in asphyxia, reduction in growth rates of the coral skeleton, and abrasion on the live coral surface (Abidin and Mohamed, 2014). Wielgus et al. (2004) have concluded that the concentration of suspended particulate matter in diving spots of Eilat is two times higher compared with the control area with the same distance and depth. Accordingly, we considered that the main factors caused by improper diving behaviors in WZZ Island included repeated touching, ammonia enrichment, and sediment cover. In our previous study (unpublished data), we have found that the growth of Porites cylindrica ( $P$. cylindrica) in the diving spots of WZZ Island is better compared with Acropora hyacinthus (A. hyacinthus). In the present study, we aimed to explore how the multiple stresses affected the physiological state of these two species and to explain the mechanisms underlying the additive or synergistic disturbance effects.

\section{MATERIALS AND METHODS}

\section{Sample Collection and Coral Maintenance}

This study was carried out in the coral culture laboratory of the Marine Institute at Hainan University between September and November 2020. The experiment for P. cylindrica and A. hyacinthus was performed separately. All coral samples were collected at 4-6 m depth from the coral nursery of WZZ located in Sanya, Hainan in July 2020. Corals from five colonies were chipped into 20 pieces (four pieces were chipped from each colony) of about $4-6 \mathrm{~cm}$ in length for each species and placed into number-labeled plates. Samples were divided into four groups and placed into plastic tanks $(41 \times 28 \times 14 \mathrm{~cm})$ containing artificial seawater. Each group was continuously aerated by a RESUN electromagnetic air pump (ACO-003, China). Water flow was maintained by a SUNSUN wave pump (HJ-211, China). The light was supplied by a SHARK fullspectrum LED lamp from 08:30 to 17:30 every day. Corals were acclimated to experimental conditions for 2 weeks until no mucus was produced and all tentacles displayed full polyp extension. Buoyant weight in seawater was determined for each sample by accurate buoyant weighing equipment (Davies, 1989) at $2 \mathrm{~h}$ before the start and end of the experiment. The skeletal growth rate of corals was expressed by the change of the results before and after the experiment.

\section{Experimental Design}

Touching, ammonia nitrogen enrichment, and sediment cover are considered key influencing factors caused by SCUBA diving. To imitate these three circumstances of improper diving behaviors, four groups were set up as follows. (1) The control group was defined as the normal culture conditions without additional treatment. (2) The entire surface of each sample in treatment group 1 was randomly touched with an appropriate strength of 15 times per day (once for $1 \mathrm{~min}$ at 30-s intervals) based on the research by Harriott et al. (1997) that the average contact of divers with corals in Marine Protected Areas of Eastern Australia is 35 times every $30 \mathrm{~min}$. This condition was used to simulate the case that coral was repeatedly touched by diving tourists. (3) In treatment group 2, in addition to touching, the water supply was switched to seawater supplemented with $5 \mu \mathrm{mol}$ $\mathrm{L}^{-1} \mathrm{NH}_{4}^{+}$prepared by G.R. ammonium chloride because the concentration of $\mathrm{NH}_{4}^{+}$in the high-intensity diving area in WZZ is $1.28-4.07 \mu \mathrm{mol} \cdot \mathrm{L}^{-1}$ in 2017 (Huang et al., 2020). This condition was used to simulate the case that coral was continuously touched in a high ammonia environment due to the urination of divers. (4) In treatment group 3, in addition to touching and high ammonia seawater, each coral was covered with $3 \mathrm{~g}$ of sediments for $40 \mathrm{~min}$ per day in a $100-\mathrm{mL}$ glass beaker in tanks. The sediments on the surface were washed with a gentle stream of water after sediment treatment. This condition was used to simulate the case that divers repeatedly touched the coral in the high ammonia diving area and disturbed the sediments on the seabed with fins. The sediment was collected from the seabed of diving spots in WZZ in November 2018, and the sediment with a particle size of less than $0.3 \mathrm{~mm}$ was screened by a 60 -mesh sieve. The experiment lasted for 10 days, and $1 / 2$ volume of seawater was replaced by suctioning the bottom every 2 days. Normal artificial seawater was used in the control group and treatment group 1, while artificial seawater containing $5 \mu \mathrm{mol} \cdot \mathrm{L}^{-1} \mathrm{NH}_{4}{ }^{+}$was used in treatment groups 2 and 3.

\section{Environmental Parameters}

Salinity, water temperature, $\mathrm{pH}$, and dissolved oxygen (DO) in each tank were recorded at 09:00 every day before the stress treatment on the same day. Salinity was determined using a BK-056 salinity monitor, and temperature and $\mathrm{pH}$ were measured using a LICHEN pen acidometer ( $\mathrm{pH}-100 \mathrm{~A}$, China). The unrelated environmental factors for different treatments were kept constant to obtain credible results. The average water temperature, $\mathrm{pH}$, and salinity were $25.1 \pm 0.1^{\circ} \mathrm{C}, 8.25 \pm 0.01$, and $34.2 \pm 0.1[n=20$, mean \pm standard error (SE)], respectively. DO of each group was determined with a Presens standalone oxygen meter (Fibox 4 trace, Germany). Turbidity and underwater light intensity were recorded at 09:00 every 2 days before each 2-day water exchange cycle using an Aquatec turbidity meter (AQUAlogger 310TY, United Kingdom) and an LI-COR (LI-1500, United States) Light Sensor Logger $(\mu \mathrm{mol}$ photons $\left.\cdot \mathrm{m}^{-2} \cdot \mathrm{s}^{-1}\right)$, respectively.

\section{Physiological Parameters and Photosynthetic Physiology}

Coral samples were collected into a sealed bag after photobiological measurements and immediately frozen at $-20^{\circ} \mathrm{C}$ before further analyses. For each physiological parameter of each species, we determined more than three biological samples in each group. The wet weights of all samples for physiological parameter analysis were about $1 \mathrm{~g}$. The parameter of each sample was measured at least three times. Tissues were washed down from the skeleton with a Waterpik flosser (WP-70EC, WaterPik, Inc.) containing filtered seawater by filter membrane (0.45 $\mu \mathrm{m}$, Whatman No. 1, United Kingdom), and 
the tissue biomass was then determined as previously described (Fitt et al., 2000). The surface area of corals was determined by wrapping up using aluminum foil (Li et al., 2006), and the tissue biomass was obtained by measuring the ash-free dry weight. Chlorophyll a (Chl a) was extracted with $100 \%$ acetone in the dark (Lei et al., 2008), and its concentration was determined with a Trilogy Laboratory Fluorometer (Turner Designs, 7200-000). Zooxanthellae density was assessed under the microscope according to a previously described method (Li et al., 2006). Carbohydrates were extracted in a trichloroacetic acid solution containing phenol and concentrated sulfuric acid (Dubios et al., 1956), and their absorbance values were measured using a TECAN spark full band microplate luminescence detector. Lipid was determined according to a previously described method (Xu et al., 2020). The coral samples were extracted with CM solution $\left(\mathrm{V}_{\text {chloroform }}: \mathrm{V}_{\text {methanol }}=1: 2\right)$, and $0.88 \% \mathrm{KCl}$ was added before the dark treatment for about $24 \mathrm{~h}$. Subsequently, the extract was dried with $\mathrm{N}_{2}$ at $39^{\circ} \mathrm{C}$. Protein concentration was determined with a modified BCA Protein Assay Kit (Sangon Biotech, China) by the bicinchoninic acid method (Smith et al., 1985). To compare physiological parameters, energy reserves (proteins, carbohydrates, and lipids), zooxanthellae densities, and the Chl a concentration were normalized to the surface area as well as the tissue biomass (Edmunds and Gates, 2002). Photosynthetic parameters of corals were determined by a mini-PAM fluorometer (Walz, Germany), and these parameters were used to assess the maximum photosynthetic yield (Fv/Fm) and light use efficiency (alpha) at 10:00-11:00 on days 1, 4, and 10. Fv/Fm is a direct measure of coral's efficiency in utilizing the light available for photosynthesis (Krause and Weis, 1991; Jones et al., 1999) and alpha reflects light use efficiency.

\section{DNA Extraction and Amplicon Sequencing}

Six samples were taken from each species for analysis of zooxanthellae clades and types. Total genomic DNA from coral samples including tissue and skeleton were extracted using CTAB/SDS method with the DNeasy Plant Mini Kit (QIAGEN, Germany). DNA concentration was measured using a NanoDrop ND-1000 spectrophotometer (NanoDrop Technologies, United States) and DNA purity was monitored on $1 \%$ agarose gels. The target fragment were amplified using the Symbiodiniaceae ITS-specific primers ITSintfor2 $\left(5^{\prime}\right.$-GATTGCAGAACTCCGTG-3') and ITS2-reverse (5' GGATCCATATGCTTAAGTTCAGCGGGT-3') (Chen et al., 2019). The volume of $P C R$ reaction was $30 \mu \mathrm{L}$. The PCR process were carried out with pre-denaturation at $98^{\circ} \mathrm{C}$ for $1 \mathrm{~min}$, followed by 30 cycles of denaturation. PCR products were detected by $2 \%$ agarose gel electrophoresis and purified with Genejet Gel Extraction Kit (Thermo Scientific, China). Sequencing was performed on the Illumina Miseq platform using the sequencing library generated with the NEB Next ${ }^{\circledR}$ Ultra $^{\text {TM }}$ DNA Library Prep Kit for Illumina (NEB, United States). The library quality was assessed on the Qubit@2.0 Fluorometer (Thermo Scientific) and Agilent Bioanalyzer 2100 system. The paired end readings of the original DNA fragments were assigned to each sample according to a unique encoding and combined using FLASH to remove redundant and invalid sequences. Operational taxonomic units (OTUs) were grouped at $97 \%$ similarity according to the method described by Tong et al. (2017). Only the OTUs of symbiotic algae were retained for subsequent analysis. The most abundant OTUs sequence selected by BLAST was used as the representative sequence for comparison with the ITS2 database for taxonomy annotation, which archives the largest number of Symbiodiniaceae ITS2 sequences known to date (Shi et al., 2020).

\section{Data Analyses}

All experiments of physiological and photosynthetic parameters were repeated at least three times, and the data were expressed as mean \pm SE. Statistical analysis was carried out using the statistical package SPSS 23.0. All data were checked for normality and homogeneity of variances using the Shapiro-Wilk test and Levene's test. The effects of treatments on physiological and photosynthetic parameters were analyzed by one-way ANOVA. $P<0.05$ was considered statistically significant, and post hoc LSD tests were run for the separation of significant factors. Principal component analysis (PCA) and Pearson's correlation were performed on the physiological and photosynthetic parameters of corals. PCA needs to meet the following conditions: (1) KMO test coefficient $>0.5$ (Kaiser and Rice, 1974) and (2) Bartlett's test $P<0.05$. Multivariate analysis of variance (MANOVA) was used to test the effects of the most essential principal components. The barplot of relative abundance for zooxanthellae types was completed using the R software.

\section{RESULTS}

\section{Environmental Parameters in Two Trials}

Turbidity and light intensity in treatment group 3 were significantly lower compared with the other groups in two trials $(P<0.05)$ (Table 1). For A. hyacinthus, the DO content in each treatment group was significantly lower compared with the control group $(P<0.05)$, and the DO content in treatment group 3 was significantly lower compared with the other two treatment groups $(P<0.05)$ (Table 1$)$. For $P$. cylindrica, the DO content in treatment group 3 was significantly lower compared with the other groups $(P<0.05)$ (Table 1$)$.

\section{Molecular Analysis of Zooxanthellae Clades and Types}

Symbiodinium subclade groups of $A$. hyacinthus and $P$. cylindrica included C3b, C3w, C15, C21, C50, C115, D2, D17 and others (Figure 1). Among them, P. cylindrica were mainly symbiotic with the zooxanthella type $\mathrm{C} 15$, while $A$. hyacinthus were mainly associated with the zooxanthella type D17 or C50.

\section{Observation of Experimental Process}

In the control group for both A. hyacinthus and P. cylindrica, all corals grew well during the experimental period. Regarding A. hyacinthus, corals in the treatment groups produced a large 
TABLE 1 | Environmental parameters for different treatments (the control, treatments 1, 2, and 3) in two trials.

\begin{tabular}{|c|c|c|c|c|c|c|}
\hline & \multicolumn{3}{|c|}{ Acropora hyacinthus } & \multicolumn{3}{|c|}{ Porites cylindrica } \\
\hline & $\begin{array}{c}\text { Turbidity } \\
\text { (FTU) }\end{array}$ & $\begin{array}{l}\text { Light intensity } \\
\qquad(\mu \mathrm{mol} \\
\left.\text { photons } \cdot \mathrm{m}^{-2} \cdot \mathrm{s}^{-1}\right)\end{array}$ & $\mathrm{DO}\left(\mathrm{mg} \cdot \mathrm{L}^{-1}\right)$ & $\begin{array}{c}\text { Turbidity } \\
\text { (FTU) }\end{array}$ & $\begin{array}{l}\text { Light intensity } \\
\qquad(\mu \mathrm{mol} \\
\left.\text { photons } \cdot \mathrm{m}^{-2} \cdot \mathrm{s}^{-1}\right)\end{array}$ & $\mathrm{DO}\left(\mathrm{mg} \cdot \mathrm{L}^{-1}\right)$ \\
\hline Control & $3.21 \pm 0.11^{a}$ & $436.8 \pm 9.3^{a}$ & $6.50 \pm 0.02^{\mathrm{a}}$ & $3.22 \pm 0.26^{a}$ & $441.8 \pm 5.8^{a}$ & $6.53 \pm 0.03^{a}$ \\
\hline Treatment 1 & $3.68 \pm 0.18^{a}$ & $460.2 \pm 9.3^{a}$ & $6.33 \pm 0.04^{b}$ & $3.23 \pm 0.18^{a}$ & $450.6 \pm 3.4^{a}$ & $6.50 \pm 0.04^{a}$ \\
\hline Treatment 2 & $3.18 \pm 0.24^{a}$ & $432.0 \pm 19.2^{a}$ & $6.37 \pm 0.04^{b}$ & $3.43 \pm 0.23^{a}$ & $446.0 \pm 7.8^{a}$ & $6.51 \pm 0.01^{a}$ \\
\hline Treatment 3 & $6.34 \pm 0.32^{b}$ & $311.2 \pm 12.9^{b}$ & $6.18 \pm 0.08^{\mathrm{c}}$ & $5.91 \pm 0.34^{b}$ & $340.2 \pm 10.7^{b}$ & $5.92 \pm 0.05^{\mathrm{b}}$ \\
\hline
\end{tabular}

Data were expressed as the mean \pm standard error (SE). Different letters in the same column indicate significant differences at $P<0.05$ level among different treatments.

amount of mucus within 15 min after they were touched every day. The coral tentacles of all treatment groups shrank on day 4 , and coral bleaching occurred in treatment group 3 on day 7 (Figures 2A,B). Unlike A. hyacinthus, the shrinking tentacles of treated corals and the mucus production were not found in treatment groups 1 and 2 for $P$. cylindrica, while mucus was produced with the sediment cover in treatment group 3. No significant color change was observed in all $P$. cylindrica-related experiments (Figures 2C,D).

\section{Effects of Different Diving Behaviors on Photosynthetic Capacity}

For A. hyacinthus, Fv/Fm and alpha were maintained at a high level throughout the experiment in the control group. The average $\mathrm{Fv} / \mathrm{Fm}$ was 0.675 , and the average alpha was 0.198 in the control group. A decreasing trend for Fv/Fm and alpha was observed with the extension of treatments. At the end of the experiment, Fv/Fm was decreased by 14,32 , and $38 \%$, and alpha was decreased by 22,42 , and $46 \%$, respectively, compared with that on day 1 in treatment groups 1,2 , and 3. On day 1, treatment group 2 was the only group, where Fv/Fm was significantly lower compared with the control group $(P<0.05)$. On day $4, \mathrm{Fv} / \mathrm{Fm}$ in treatment group 1 began to significantly decrease compared with the control group $(P<0.05)$, while Fv/Fm in treatment group 3 remained at a high level. Fv/Fm in treatment group 3 showed a significant decrease until day $10(P<0.05)$ (Figure $3 \mathbf{A})$. No significant differences in alpha were found in all groups on day 1 , while the relationship between groups was consistent with Fv/Fm on day 4. At the end of the experiment, alpha in all treatment groups was significantly lower compared with the control group $(P<0.05)$, while no significant difference in alpha was found between treatment groups 2 and $3(P<0.05)$ (Figure 3B).

For $P$. cylindrica, Fv/Fm and alpha were maintained at a high level throughout the experiment in the control group. The average $\mathrm{Fv} / \mathrm{Fm}$ was 0.614 , and the average alpha was 0.185 in the control group. On days 1, 4, and 10, there were significant differences in Fv/Fm among groups, and the magnitude of the decrease in $\mathrm{Fv} / \mathrm{Fm}$ was increased as the stress factors were increased (Figure 3C). At the end of the experiment, Fv/Fm was decreased by 13,14 , and $13 \%$ in treatment groups 1,2 , and 3 compared with that on day 1 , respectively. The trend of alpha in each group was basically similar to that of Fv/Fm, while there was a time lag for alpha compared with Fv/Fm. Only alpha in treatment group 3 was significantly lower compared with the other groups on day $1(P<0.05)$, while alpha in treatment groups 2 and 3 was significantly different from that in the control group on day $4(P<0.01)$. At the end of the experiment, no significant difference was found between treatment groups 2 and $3(P>0.05)$ (Figure 3D). Unlike $A$. hyacinthus, the declining range of each treatment was small after day 4 though a dramatic decrease was observed before day 4 .

\section{Effects of Different Diving Behaviors on Physiological States}

For A. hyacinthus, the zooxanthellae density in treatment group 1 was decreased by $15 \%$ compared with the control group $(P<0.01)$, and it was increased by $23 \%$ in treatment group 2 compared with treatment group $1(P<0.01)$, with the lowest density observed in treatment group 3 (Figure 4A). The Chl a concentration in treatment group 2 was decreased by $36 \%$ compared with treatment group $1(P<0.05)$, and the $\mathrm{Chl}$ a concentration in both groups was significantly higher compared with treatment group $3(P<0.05)$ (Figure 4B). The carbohydrate concentrations in treatment groups 1,2 , and 3 were decreased by 25,35 , and $38 \%$, respectively, compared with the control group $(P<0.01)$, and the carbohydrate concentrations in treatment groups 2 and 3 were extremely lower compared with treatment group $1(P<0.01)$. However, there was no significant difference in carbohydrate concentrations between treatment groups 2 and 3 (Figure 4C). The lipid concentration in treatment group 2 was increased by $63 \%$ compared with treatment group $1(P<0.01)$, while the lipid concentration in treatment group 3 was decreased compared with the control group and treatment group 2 by 27 and $42 \%$, respectively $(P<0.05)$ (Figure 4D). The significant differences in protein concentrations $(P<0.01)$ were noted in each treatment group compared with the control group. Specifically, a reduction of $11 \%$ was observed for treatment group 1 compared with the control group, whereas there was an increase of 39 and $6 \%$ in treatment groups 2 and 3, respectively. The lipid concentration in treatment group 3 was significantly lower compared with treatment group $2(P<0.01)$ (Figure $4 \mathrm{E})$. There was no significant difference in tissue biomass between treatments, except that the tissue biomass in treatment group 2 was significantly reduced by $28 \%$ compared with treatment group $1(P<0.05)$ (Figure $4 \mathbf{F})$. The skeletal growth rate in treatment group 1 was reduced by $72 \%$ compared with the 


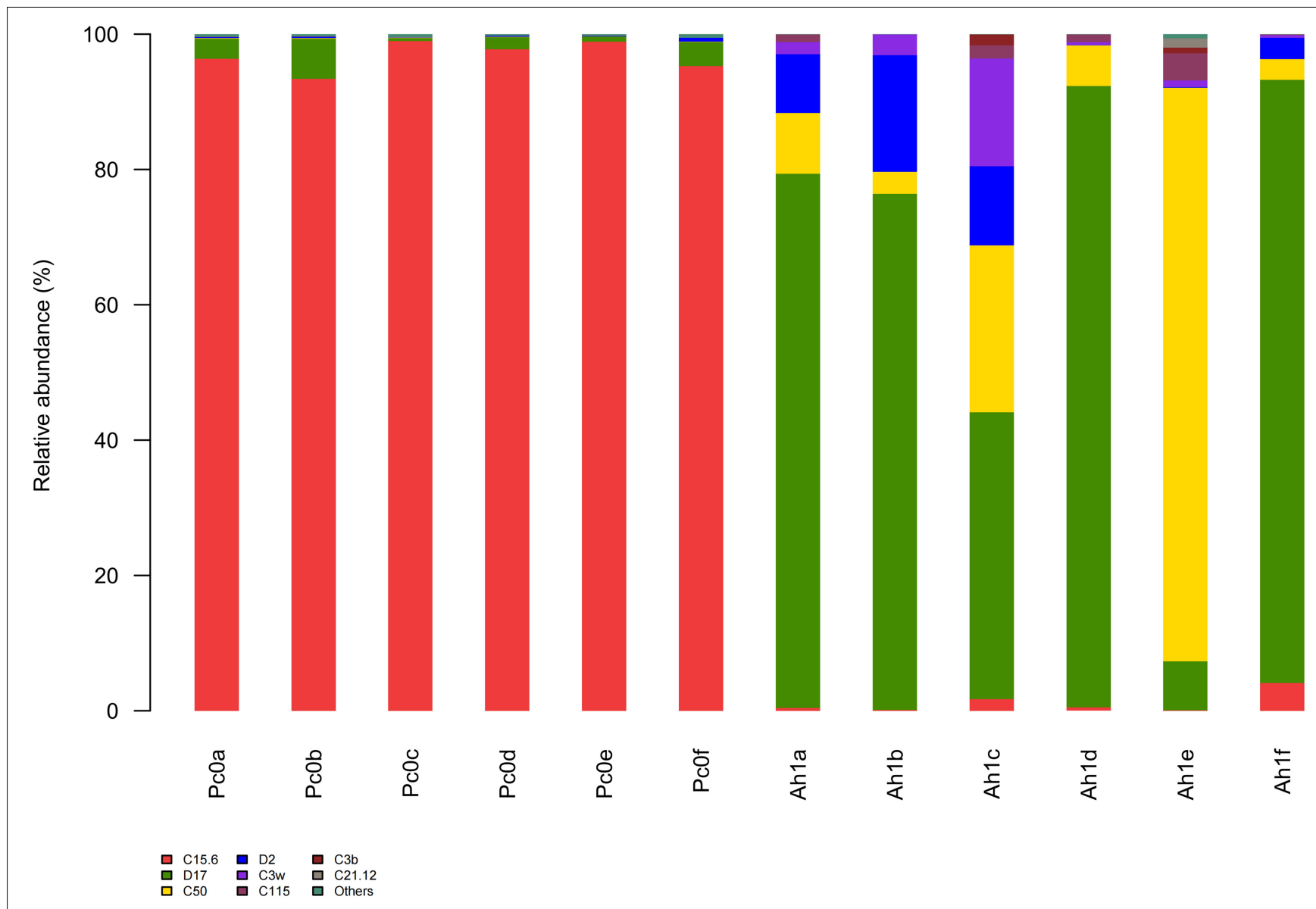

FIGURE 1 | Relative abundance of zooxanthellae types for A. hyacinthus (Ah1a-Ah1f) and P. cylindrica (PcOa-Pc0f). Six samples were taken from each species for analysis.

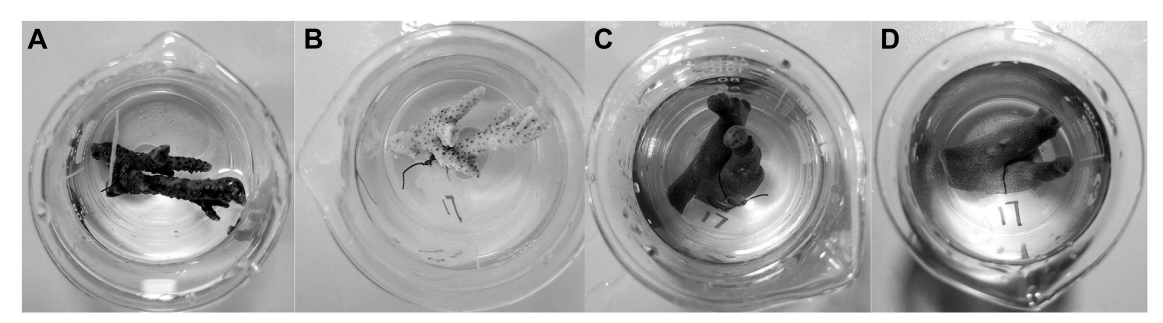

FIGURE 2 | Photographs of representative samples before (A) for A. hyacinthus and (C) for P. cylindrica and after (B) for A. hyacinthus and (D) for P. cylindrica experiments in treatment group 3. The sample of $A$. hyacinthus in treatment group 3 bleached at the end of the experiment, while no significant color change in $P$. cylindrica was observed in treatment group 3.

control group $(P<0.01)$. A highly significant negative increase in the skeletal growth rate was found in both treatment groups 2 and $3(P<0.01)$, and the negative skeletal growth rate in treatment group 3 was extremely higher compared with treatment group 2 $(P<0.05)$ (Figure 4G).

For $P$. cylindrica, the zooxanthellae density in treatment groups 1 and 2 were significantly increased by 64 and $89 \%$ $(P<0.01)$ compared with the control group, respectively, while it in treatment group 3 was significantly decreased compared with treatment groups 1 and 2 by 35 and 43\%, respectively $(P<0.01)$ (Figure 4H). The $\mathrm{Chl}$ a concentration in treatment group 2 was significantly decreased by 17 and $23 \%$ compared with the control group and treatment group $1(P<0.01)$, respectively, while the $\mathrm{Chl}$ a concentration in treatment group 3 was significantly increased by $13 \%$ compared with treatment group $2(P<0.05)$ (Figure 4I). Significant differences in carbohydrate concentrations were found between treatment groups. The carbohydrate concentrations in treatment groups 


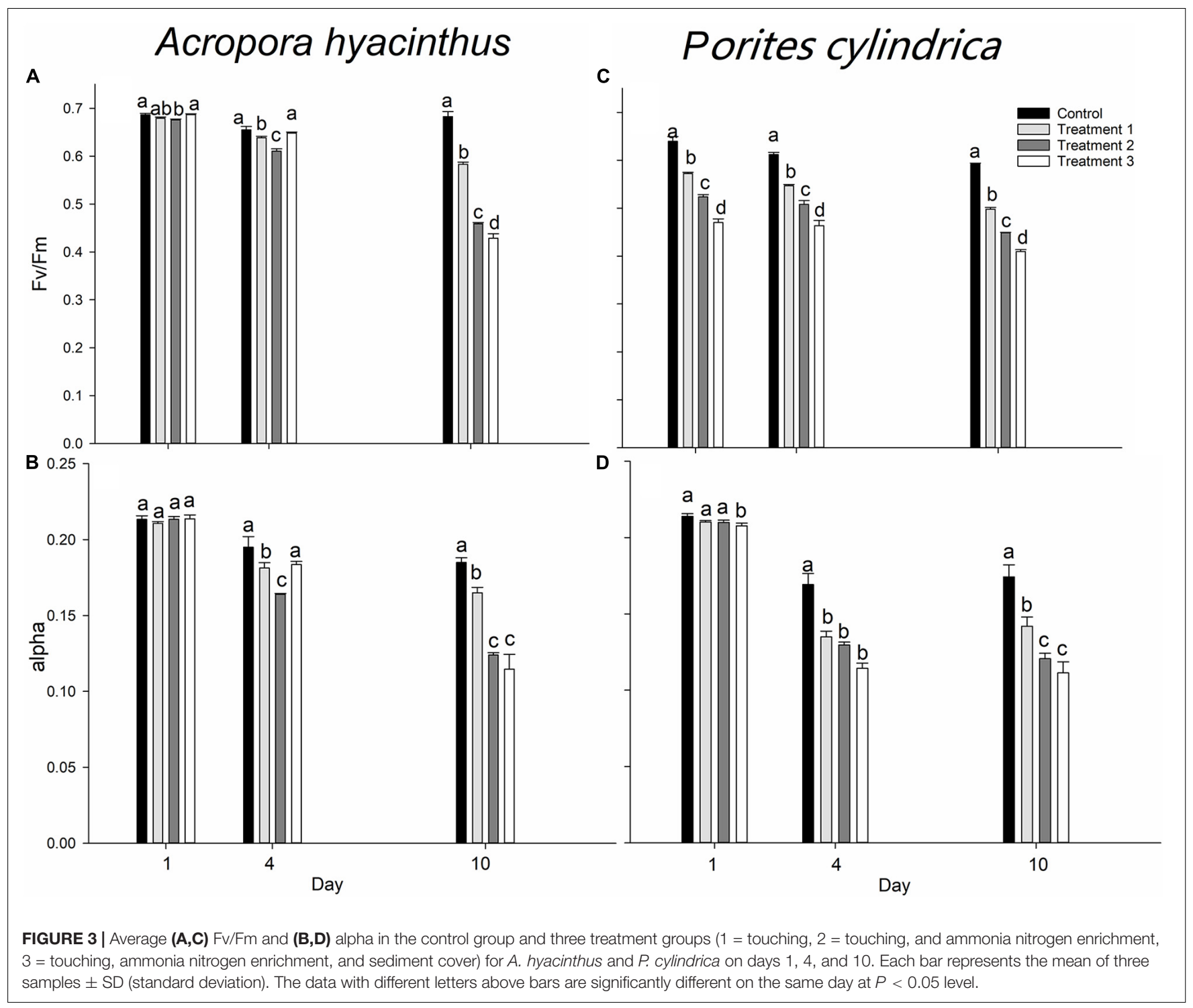

1,2 , and 3 were decreased by 15,18 , and $36 \%$, respectively, compared with the control group $(P<0.01)$, and the increase of stress factors resulted in a significant decrease in carbohydrate concentrations $(P<0.05)$ (Figure 4J). The lipid concentration in treatment group 2 was significantly lower compared with the other groups $(P<0.01)$ (Figure $4 \mathrm{~K})$. The lipid concentration in treatment group 3 was decreased by 41 and $39 \%(P<0.01)$, respectively, compared with the control group and treatment group 1, while it was significantly increased by $25 \%$ compared with treatment group $2(P<0.01)$. The protein concentrations in treatment groups 1,2 , and 3 were significantly lower compared with the control group by 7,49 , and $22 \%$, respectively $(P<0.05)$, and it in treatment group 3 was significantly increased (55\%) compared with treatment group $2(P<0.01)$ (Figure $4 \mathbf{L})$. No significant difference in the tissue biomass was observed among different treatment groups, except that it in treatment group 3 was significantly lower compared with treatment groups 1 and 2 $(P<0.05)$ (Figure $4 \mathrm{M})$. The skeletal growth rate was significantly different among groups. Negative skeletal growth rates were found in all treatment groups, and the negative skeletal growth became more significant as the stress factors were increased $(P<0.01)($ Figure $4 \mathbf{N})$.

\section{Correlation Between Physiological Parameters and Photosynthetic Capacity in Two Species}

Principal component analysis of seven physiological parameters compiled for the control and treatments showed the differences between the two species. For A. hyacinthus, PCA generated factor 1 and factor 2 that described 46.8 and $36.2 \%$ of the variance, respectively (Table 2). Factor 1 was characterized by high positive component loadings for skeletal growth rate, carbohydrates, zooxanthellae density, and $\mathrm{Chl}$ a concentration. Factor 2 was characterized by high positive component loadings for proteins and lipids and by a negative component loading 
A

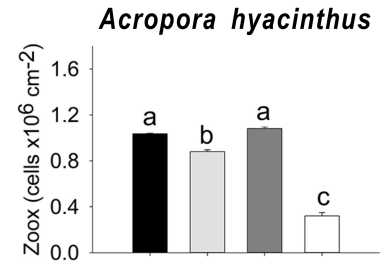

B

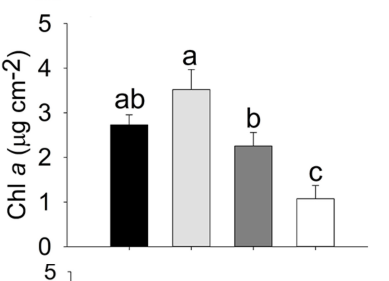

C

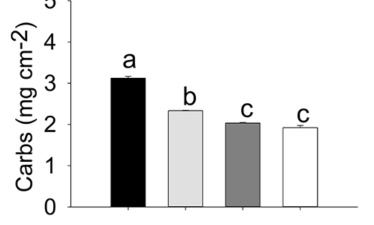

D

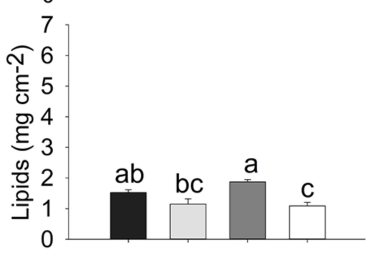

E

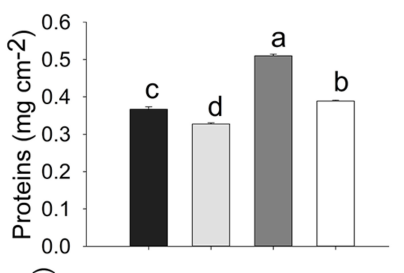

$\mathbf{F}$

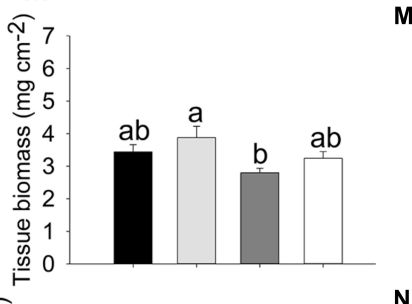

G

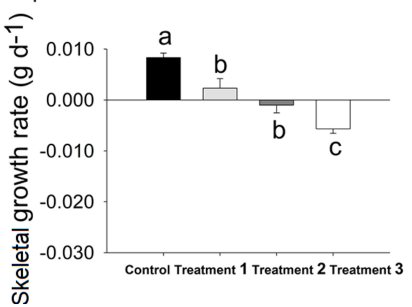

\section{Porites cylindrica}

H. a a

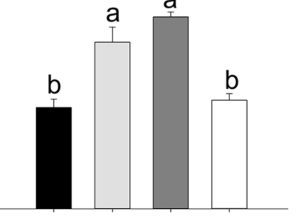

I $a$

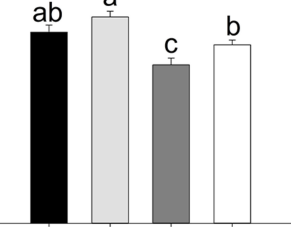

J $\quad$ a

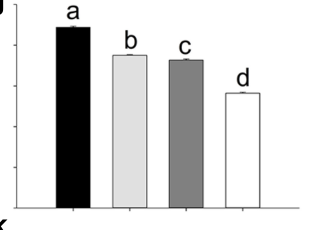

K a

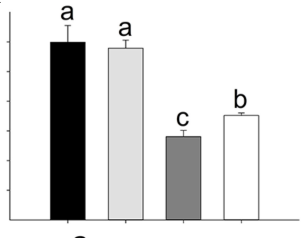

L $\stackrel{a}{a} b$

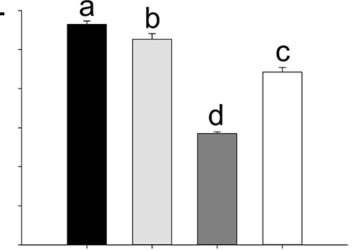

M
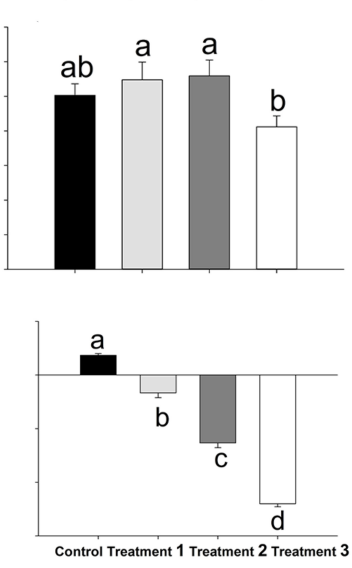

FIGURE 4 | Average (A,H) zooxanthellae density (Zoox), (B,I) Chl a concentration, (C,J) carbohydrate concentration (Carbs), (D,K) lipid concentration, (E,L) protein concentration, (F,M) tissue biomass, and $\mathbf{( G , N )}$ skeletal growth rate in the control group and three treatment groups $(1=$ touching, $2=$ touching, and ammonia nitrogen enrichment, 3 = touching, ammonia nitrogen enrichment, and sediment cover) for $A$. hyacinthus and $P$. cylindrica. Each bar represents the mean of three samples $\pm \mathrm{SD}$ (standard deviation). The data with different letters above bars are significantly different at $P<0.05$ level.

for tissue biomass (Table 2; Figure 5A). For $P$. cylindrica, factor 1 and factor 2 described 55.8 and $27.0 \%$ of the variance (Table 2), respectively. Factor 1 was characterized by high positive component loadings for proteins, lipids, and Chl a concentration and by a negative component loading for zooxanthellae density. Factor 2 was characterized by high positive component loadings 
for tissue biomass, carbohydrates, and skeletal growth rate (Table 2; Figure 5B). MANOVA for the most important principal component (factor 1) showed that skeletal growth rate, $\mathrm{Chl}$ a concentration, zooxanthellae density, and carbohydrates were significantly different among treated A. hyacinthus samples (MANOVA: Wilk's $\lambda=0.000, F=71.572$, df $=12,14, P \leq 0.00$ ). The health conditions of $P$. cylindrica significantly differed in protein, lipid, and Chl a (MANOVA: Wilk's $\lambda=0.003$, $F=15.914$, df $=9,15$, and $P=0.00)$. Furthermore, correlation analyses demonstrated that Fv/Fm and alpha were both positively correlated with skeletal growth rate, $\mathrm{Chl}$ a concentration, and zooxanthellae density for $A$. hyacinthus $(r>0.5, P<0.05$, Figure 5C), and they were correlated with carbohydrates, lipids, protein and skeletal growth rate for $P$. cylindrica $(r<0.5$, $P>0.05$, Figure 5D). Besides, Fv/Fm and alpha were significantly correlated with each other in two species $(r<0.5, P>0.05$; Figures 5C,D).

\section{DISCUSSION}

\section{Effects of Touching on Two Species}

Regarding A. hyacinthus, the tentacles obviously retracted upon repeated touching, which was frequently the first response to appear under stressful conditions (Chen et al., 2017). Corals after being touched secreted large amounts of mucus. Releasing mucus on a prolonged basis introduces adverse impacts on the health of corals (Howard and Brown, 1984), and zooxanthellae can be released (Riegl and Branch, 1995). This is consistent with the fact that the zooxanthellae density is decreased after being touched (Chen et al., 2017). Although mucus consists of high concentrations of proteins, lipids, and polysaccharides that favor bacterial growth (Ferrier-Pagès et al., 2000; Wild et al., 2004), the higher density of microorganisms in the mucus increased the oxygen consumption, resulting in decreased DO compared with the control group.

Regarding $P$. cylindrica, we didn't observe the retraction of coral tentacles and secretion of mucus after being touched, illustrating that this species could well adapt to mild stress. We speculated that the dissolved nutrients brought by touching stimulated the growth of algae, resulting in a significant increase of zooxanthellae density, which needs to be proved in future experiments.

Two species both regarded lipid as priority energy reserved after being touched by decreasing the concentrations of carbohydrate and protein. And tissue biomass remained stable. They reduced the skeletal growth rate and photosynthetic capacity to maintain survival in that case.

\section{Effects of Touching and Ammonia Nitrogen Enrichment on Two Species}

Regarding A. hyacinthus, zooxanthellae density in this treatment was significantly higher than that of the touched group, which suggested that zooxanthellae greatly depended on high nutrient and $A$. hyacinthus preferred to adjust autotrophy strategy under stress. Zhu et al. (2004) also found that the zooxanthellae density increased when the content of ammonia nitrogen was over $1 \mu \mathrm{mol} \cdot \mathrm{L}^{-1}$. These symbiotic dinoflagellates may take up nitrate with ammonium available in the seawater (Fitt et al., 2000). These corals grow healthfully through the delivery of photosynthesis products from abundant zooxanthellae to the host under the conditions of high DIN and low heterotrophic feeding (Gustafsson et al., 2013). The concentration of Chl a, as a signal of nutrient sufficiency (Muscatine et al., 1989), declined significantly compared with the touched corals. The Chl a concentration and zooxanthellae density in corals showed opposite changes when exposed to elevated ammonia, which suggests that nutrients are limited to zooxanthellae in that case (Jones and Yellowlees, 1997). Nevertheless, the increase in the zooxanthellae density may lead to an increase in shading among algae cells and a proportional decrease in the irradiance experienced by the zooxanthellae (Dubinsky et al., 1990). As a result, symbiotic algal photosynthetic capacity would be inhibited, and both the magnitude and speed of decline in Fv/Fm and alpha were more greatly enhanced over time compared with touching alone.

Similar to a previous study (Muscatine et al., 1989), we found that the carbohydrate concentration of A. hyacinthus further decreased for N-treated corals. Zooxanthellae have to consume a larger amount of the photosynthetically assimilated carbon for physiological activities under stressful conditions (Dubinsky et al., 1990; Long et al., 1994). This explains a large decrease in carbohydrates, as the energy material with the highest percentage in corals, leading to the negative growth under double stresses of touching and ammonia nitrogen enrichment. Tissue biomass was declined significantly compared the corals only being touched. As an estimate of the energy devoted to maintenance (Precoda et al., 2020), tissue biomass within a coral species can vary with water quality (Cooper et al., 2009), such as in ammonia nitrogen enrichment. Muscatine et al. (1989) have believed that algal protein synthesis in vivo is $\mathrm{N}$ limited, and abundant zooxanthellae can take up ammonium for protein synthesis, which was also found in our experiment. As lipids play an important role in resilience (Grottoli et al., 2004; Levas et al., 2018; Solomon et al., 2020), higher lipid concentration than that of the touching group improves the adaptability to nutrient enrichment and repeated touching.

The interaction of ammonia enrichment and repeated touching increased the negative impacts of touching on energy reserves for $P$. cylindrica. The massive loss of all energy reserves caused a more significant negative skeletal growth rate. The Chl a concentration also declined significantly, but nutrient didn't significantly increase zooxanthellae density compared with the touched group to relieve stress like A. hyacinthus. $P$. cylindrica can not maintain adequate autotrophic input in high nutrient seawater and eutrophication is extremely unfavorable to the physiological activities of $P$. cylindrica.

\section{Effects of Touching, Ammonia Nitrogen Enrichment, and Sediment Cover on Two Species}

The sediment cover had the most significant adverse effect on A. hyacinthus among three factors caused by improper diving behaviors. Since corals are rapidly acclimating to the reductions 
TABLE 2 | PCA of seven physiological parameters compiled from different treatments in two species.

\begin{tabular}{|c|c|c|c|c|}
\hline & \multicolumn{2}{|c|}{ Acropora hyacinthus } & \multicolumn{2}{|c|}{ Porites cylindrica } \\
\hline & Factor 1 & Factor 2 & Factor 1 & Factor 2 \\
\hline Eigen values & 3.3 & 2.5 & 3.9 & 1.9 \\
\hline Explained variance (\%) & 46.8 & 36.2 & 55.8 & 27.0 \\
\hline \multicolumn{5}{|l|}{ Component loadings } \\
\hline Carbohydrates & 0.829 & -0.152 & 0.445 & 0.769 \\
\hline Lipids & 0.340 & 0.888 & 0.909 & 0.353 \\
\hline Proteins & -0.227 & 0.907 & 0.980 & 0.038 \\
\hline Tissue biomass & 0.374 & -0.816 & -0.153 & 0.835 \\
\hline Zooxanthellae density & 0.833 & 0.477 & -0.712 & 0.506 \\
\hline Chl a & 0.794 & -0.291 & 0.804 & 0.201 \\
\hline Skeletal growth rate & 0.938 & -0.064 & 0.573 & 0.769 \\
\hline
\end{tabular}

PCA generated two principal components, factor 1 and factor 2. Factor 1 explained 46.8 and 55.8\% of the variance for A. hyacinthus and P. cylindrica, respectively. Factor 2 explained 36.2 and $27.0 \%$ of the variance for A. hyacinthus and P. cylindrica, respectively. Taken together, they explained about 83.1 and $82.8 \%$ of the variation in these two species, respectively. The numbers in bold indicate the values that contributed more than 0.7 of variance.

in light (Browne et al., 2014), the Fv/Fm and alpha were not changed significantly compared with the control group at the beginning. However, exposure to sediment for a long time stresses corals to have high turbidity and limited light for photosynthesis (Anthony and Hoegh-Guldberg, 2003). Even in nutrientenriched environments, high sediment loads lead to reduced endosymbiont photosynthetic capacity (Rogers, 1990; Fabricius, 2005). Elevated turbidity also increases respiration, thereby reducing the $\mathrm{P} / \mathrm{R}$ ratio, which increases coral susceptibility to infection as well as bleaching (Rogers, 1990; Anthony and Fabricius, 2000; Anthony et al., 2007). It explained the reason why the DO of this treatment was much lower compared with the other groups. Furthermore, corals have to constantly remove sediments to aid photosynthesis, leading to the consumption of more protein and lipid (Brown and Bythell, 2005; Fabricius, 2005; Flores et al., 2012), and thus causing the more significant negative growth in this treatment. Since prolonged light attenuation will result in the dissociation of the coral-algal symbiosis (Glynn, 1996; Brown, 1997; Desalvo et al., 2012), zooxanthellae density under this condition was significantly reduced. The corals might release the weak zooxanthellae and combine with other robust zooxanthellae (Xu et al., 2020) to reply to high turbidity, ammonia nitrogen enrichment, and repeated touching. Corals in this treatment bleached caused by the great loss of zooxanthellae density and $\mathrm{Chl}$ a. A. hyacinthus relies heavily on phototrophy and they will bleach once the phototrophic capacity are inhibited. Meanwhile, nutrient composition and microbial activity in sediment accelerate the bleaching process (Weber et al., 2006, 2012).

Different from A. hyacinthus, Fv/Fm and alpha of P. cylindrica under the stress of three factors showed a sharp decline at the beginning of the experiment but then remained stable, indicating that $P$. cylindrica could adapt to long-term sediment stress. P. cylindrica chose to increase the $\mathrm{Chl}$ a concentration compared with treatment group 2 to cope with the declines in light availability (Rogers, 1979; Dubinsky et al., 1984), which was in response to the decrease of zooxanthellae density. Unlike A. hyacinthus, although the carbohydrate concentration, as the first energy reserves to consume, was further decreased, the protein and lipid concentrations of $P$. cylindrica were significantly higher compared with the treatment group of touching and ammonia nitrogen enrichment, which might be related to heterotrophic feeding. Porites associated with C15 zooxanthella can survive a highly turbid environment (Sudara and Yeemin, 1997) and increase heterotrophic feeding to compensate for restricted symbiodiniaceae photosynthesis under high turbidity conditions (Ferrier-Pagès et al., 2011). Some corals can use a wide range of food sources, including suspended particulate matter (Anthony, 1999; Anthony and Fabricius, 2000) and sediment (Mills and Sebens, 2004; Mills et al., 2004), which may offer rich sources of energy (Anthony and Fabricius, 2000; Anthony, 2006). The heterotrophic plasticity of corals offset stress from extreme sedimentary loads, and the change in the trophic mode is a mechanism to keep positive energy balance under turbid conditions and broaden physiological niche (Anthony and Fabricius, 2000). A. hyacinthus were mainly associated with D17 zooxanthella. Nevertheless, no studies showed the physiological characteristics of D17 zooxanthella and we also didn't carry out the relevant research in this experiment. We need further exploration in the future work.

Porites cylindrica has always become the dominant species on reef slop with elevated levels of sedimentation (Browne et al., 2014). Producing mucus and sweep tentacles to slough off sediments (Stafford-Smith and Ormond, 1992; Stafford-Smith, 1993; Brown and Bythell, 2005) is beneficial for P. cylindrica to tolerating higher rates of sedimentation, while sediment exclusion mechanism was not found in treatment group 3 of A. hyacinthus. Nevertheless, producing mucus is an extremely costly way of responding to pressure compared with the release of carbon equivalent accumulated in several days (Riegl and Branch, 1995). Therefore, the corals in treatment group 3 had more significant negative skeletal growth compared with other treatments. Many coral reef communities near-shore disturbed by frequent sediment stress have adapted to low light and high sedimentation rates (Perry et al., 2009; Browne et al., 2010). Based on the fact that $P$. cylindrica is the dominant species in the 


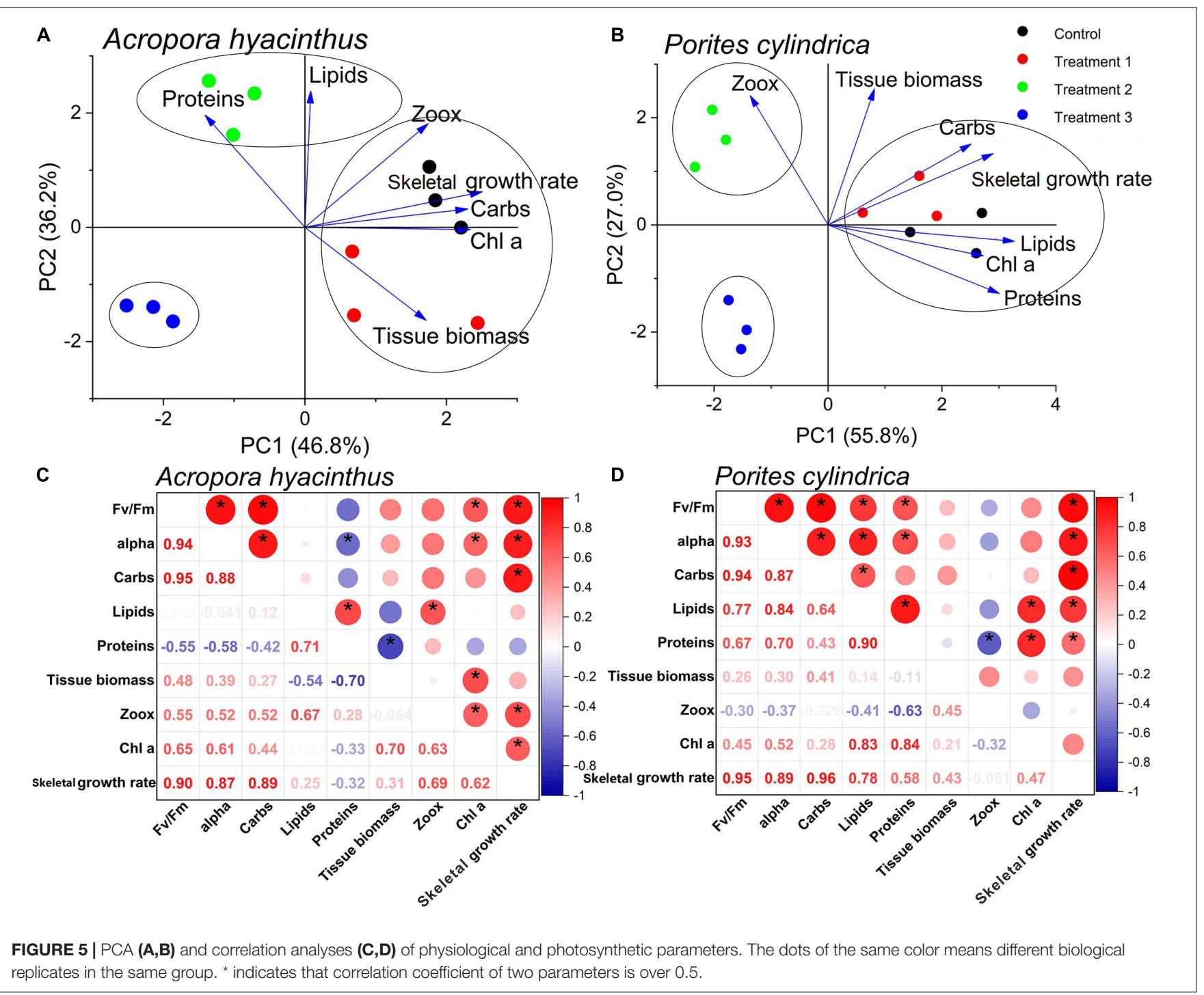

diving areas, such as the north of WZZ, it was more adaptable to the diving environment with repeated touching, high ammonia nitrogen, and frequent sediment cover.

\section{Comparison of Coping Mechanism for Diving Activities of Two Species}

Acropora hyacinthus and Porites cylindrica both preferentially decrease photosynthetic capacity and skeletal growth rate when encountering stress and the magnitude of decline will be increased as the stress factors are increased. In our short-term experiment, no obvious changes in tissue biomass are found in different groups, indicating that corals guarantee survival by reducing the rate of growth and calcification. For energy budget of two species, carbohydrate is the first energy reserve to consume in a stressful environment and decreases as the stress factors are increased, followed by protein. Lipid plays an important role in corals' stress resistance and is always consumed under severe stress.
Two species have different physiological mechanisms when coping with stresses. (1) A. hyacinthus is more adaptable to the eutrophic water than $P$. cylindrica and can increase zooxanthellae density to maintain autotrophic input. (2) A. hyacinthus only relies on photoautotrophy under stress. However, heterotrophy can be crucial in maintaining the physiological functions of $P$. cylindrica due to $\mathrm{C} 15$ zooxanthella when autotrophy is depressed. (3) The photosynthetic capacity of $P$. cylindrica is more stable, especially in long-term sediment stress. The magnitude decrease of $\mathrm{Fv} / \mathrm{Fm}$ and alpha for P. cylindrica was less than A. hyacinthus in the last period of the experiment. (4) $P$. cylindrica is more inclined to employ energy to sweep tentacles or produce mucus for self-protection, reducing the probability of bleaching (Fitt et al., 2009). Nevertheless, A. hyacinthus prefers to consume energy for fast growth and are more susceptible to environmental stresses (Hoegh-Guldberg and Smith, 1989; Jokiel and Coles, 1990).

The above-mentioned points explained why the coverage of P. cylindrica was higher than A. hyacinthus in diving areas 
of WZZ Island from the physiological state of corals, which laid the foundation for the choice of coral restoration species to address widespread stresses caused by diving activities. Studies have shown that $P$. cylindrica exhibits relatively good survival when transplanted compared with Acropora spp. which is highly susceptible to bleaching (Seebauer, 2001; Dizon and Yap, 2006; Palomar et al., 2009; Linares et al., 2011). It is likely that the remarkable acclimation and recovery capacity will make $P$. cylindrica more competitive than many other species in diving activities.

\section{CONCLUSION}

In the present study, we showed that A. hyacinthus and $P$. cylindrica responded to multiple environmental stresses caused by various diving behaviors through different mechanisms. A. hyacinthus might be more susceptible to improper diving activities compared with $P$. cylindrica in WZZ. Our results showed that relative stable photosynthetic capacity, special selfprotective mechanism, the utilization of heterotrophic nutrition, and C15 zooxanthellae with high adaptability to turbidity were important factors for P. cylindrica to survive in the diving spots of WZZ when confronting anthropogenic stresses. To alleviate the negative impacts of divers on the reefs and to keep sustainable development of diving activities, we should protect the coral community in diving spots. Diving coaches must train the tourists before diving and strengthen the supervision of their behaviors. Meanwhile, seasonal rotation of the diving sites is necessary to control the tourists' capacity and give corals time to recover. Besides, it is also necessary to regularly evaluate water quality and corals' health status in diving areas. If corals are in a poor physiological state, protection measures should be taken in time. When the coverage of living corals in diving areas is significantly decreased and corals can not be recovered only by passive restoration, the corals with strong stress resistance, such as $P$. cylindrica, can be transplanted to restore the ecological environment. In summary, effective management interventions

\section{REFERENCES}

Abidin, S. Z. Z., and Mohamed, B. (2014). A review of SCUBA diving impacts and implication for coral reefs conservation and tourism management. SHS Web Conf. 12:01093. doi: 10.1051/shsconf/20141201093

Altizer, S., Ostfeld, R. S., Johnson, P. T. J., Kutz, S., and Harvell, C. D. (2013). Climate change and infectious diseases: from evidence to a predictive framework. Science 341, 514-519. doi: 10.1126/science.1239401

Anthony, K. R. N. (1999). Coral suspension feeding on fine particulate matter. J. Exp. Mar. Biol. Ecol. 232, 85-106. doi: 10.1016/S0022-0981(98)00099-9

Anthony, K. R. N. (2006). Enhanced energy status of corals on coastal, highturbidity reefs. Mar. Ecol. Prog. Ser. 319, 111-116. doi: 10.3354/meps319111

Anthony, K. R. N., and Fabricius, K. E. (2000). Shifting roles of heterotrophy and autotrophy in coral energetics under varying turbidity. J. Exp. Mar. Biol. Ecol. 252, 221-253. doi: 10.1016/S0022-0981(00)00237-9

Anthony, K. R. N., Connolly, S. R., and Hoegh-Guldberg, O. (2007). Bleaching, energetics, and coral mortality risk: Effects of temperature, light, and sediment regime. Limnol. Oceanogr. 52, 716-726. doi: 10.4319/lo.2007.52.2.0716

Anthony, K. R., and Hoegh-Guldberg, O. (2003). Kinetics of photoacclimation in corals. Oecologia 134, 23-31. doi: 10.2307/4223470 should be taken to reduce the negative impacts of SCUBA diving and to secure the sustainability of the tourism industry and coastal resources.

\section{DATA AVAILABILITY STATEMENT}

The original contributions presented in the study are included in the article/supplementary materials, further inquiries can be directed to the corresponding author/s.

\section{AUTHOR CONTRIBUTIONS}

YZ: data curation, investigation, and writing - original draft preparation. JH: investigation and data curation. XinL, CS, JX, and YR: investigation. AW: supervision and funding acquisition. XiuL: writing, reviewing, and editing, supervision, and funding acquisition. All authors contributed to the article and approved the submitted version.

\section{FUNDING}

This work was financially supported by the Hainan Provincial Key Research and Development Program (ZDYF2020177), the National Natural Science Foundation of China (42076108), Innovation and Entrepreneurship Training Project for College Students of Hainan University in 2020, Undergraduate Innovative Experimental Project of College of Marine Science, Hainan University in 2020 and Foundation of Hainan University [KYQD(ZR)1805].

\section{ACKNOWLEDGMENTS}

The authors were grateful for constructive suggestions and technical support from the instructor and all the members of the laboratory.

Au, C. S., Zhang, L., Chung, S. S., and Qiu, J. W. (2014). Diving associated coral breakage in Hong Kong: Differential susceptibility to damage. Mar. Pollut. Bull. 85, 789-796. doi: 10.1016/j.marpolbul.2014.01.024

Barker, N. H. L., and Roberts, C. M. (2004). Scuba diver behaviour and the management of diving impacts on coral reefs. Biol. Conserv. 120, 481-489. doi: 10.1016/j.biocon.2004.03.021

Brown, B. E. (1997). Coral bleaching: causes and consequences. Coral Reefs 16, 129-138. doi: 10.1007/s003380050249

Brown, B. E., and Bythell, J. C. (2005). Perspectives on mucus secretion in reef corals. Mar. Ecol. Prog. Ser. 296, 291-309. doi: 10.3354/meps29 6291

Browne, N. K., Precht, E., Last, K. S., and Todd, P. A. (2014). Photo-physiological costs associated with acute sediment stress events in three near-shore turbid water corals. Mar. Ecol. Prog. Ser. 502, 129-143. doi: 10.3354/meps10714

Browne, N. K., Smithers, S. G., and Perry, C. T. (2010). Geomorphology and community structure of middle reef, central great barrier reef, australia: an inner-shelf turbid zone reef subject to episodic mortality events. Coral Reefs 29, 683-689. doi: 10.1007/s00338-010-0640-3

Carilli, J. E., Norris, R. D., Black, B., Walsh, S. M., and Mcfield, M. (2010). Centuryscale records of coral growth rates indicate that local stressors reduce coral 
thermal tolerance threshold. Glob. Change Biol. 16, 1247-1257. doi: 10.1111/ j.1365-2486.2009.02043.x

Chen, B., Yu, K., Liang, J., Huang, W., and Wang, Y. (2019). Latitudinal variation in the molecular diversity and community composition of symbiodiniaceae in coral from the south china sea. Front. Microbiol. 10:1278. doi: 10.3389/fmicb. 2019.01278

Chen, Y., Ma, J., Huang, H., Chen, P., Chao, F., and Luo, W. (2017). Effects of temperature, $\mathrm{pH}, \mathrm{Ammonia}$ Nitrogen content and salinity on coral (Acropora millepora\&Palythoa sp.) bleaching. Agric. Biotechnol. 6, 52-56. doi: 10.19759/j. cnki.2164-4993.2017.06.015

Cooper, T. F., Gilmour, J. P., and Fabricius, K. E. (2009). Bioindicators of changes in water quality on coral reefs: review and recommendations for monitoring programmes. Coral Reefs 28, 589-606. doi: 10.1007/s00338-009-0512-x

Crehan, O., Mair, J., Yii, S. H., Safuan, C. D. M., and Bachok, Z. (2019). Effect of tourism and sedimentation on coral cover and community structure. Trop. Life Sci. Res. 30, 149-165. doi: 10.21315/tlsr2019.30.2.11

Davies, P. S. (1989). Short-term growth measurements of corals using an accurate buoyant weighing technique. Mar. Biol. 101, 389-395. doi: 10.1007/ BF00428135

De, K., Nanajkar, M., Mote, S. G., and Ingole, B. S. (2020). Coral damage by recreational diving activities in a Marine Protected area of india: unaccountability leading to 'tragedy of the not so common. Mar. Pollut. Bull. 155:111190. doi: 10.1016/j.marpolbul.2020.111190

Dearden, P., Bennett, M., and Rollins, R. (2007). Perceptions of diving impacts and implications for reef conservation. Coast. Manage. 35, 305-317. doi: 10.1080/ 08920750601169584

Desalvo, M. K., Estrada, A., Sunagawa, S., and Medina, M. (2012). Transcriptomic responses to darkness stress point to common coral bleaching mechanisms. Coral Reefs 31, 215-228. doi: 10.1007/s00338-011-0833-4

Dinsdale, E. A., and Harriott, V. J. (2004). Assessing anchor damage on coral reefs: a case study in selection of environmental indicators. Environ. Manage. 33, 126-139. doi: 10.1007/s00267-003-3056-9

Dizon, R. T. and Yap, H. T. (2006). Effects of coral transplantation in sites of varying distances and environmental conditions. Mar. Biol. 148, 933-943. doi: 10.1007/s00227-005-0142-y

Dubinsky, Z., Falkowski, P. G., Porter, J. W., and Muscatine, L. (1984). Absorption and utilization of radiant energy by light- and shade-adapted colonies of the hermatypic coral Stylophora pistillata. Proc. R. Soc. Lond. B 222, 203-214. doi: 10.1098/rspb.1984.0059

Dubinsky, Z., Stambler, N., Ben-Zion, M., Mccloskey, L. R., and Falkowski, L. M. G. (1990). The effect of external nutrient resources on the optical properties and photosynthetic efficiency of Stylophora pistillata. Proc. R. Soc. Lond. B 239, 231-246. doi: 10.2307/49487

Dubios, M., Gilles, K. A., Hamilton, J. K., Rebers, P. A., and Smith, F. (1956). Colorimetric method for determination of sugar and related substances. Anal. Chem. 28, 250-256. doi: 10.1021/ac60111a017

Edmunds, P. J., and Gates, A. R. D. (2002). Normalizing physiological data for scleractinian corals. Coral Reefs 21, 193-197. doi: 10.1007/s00338-002-0214-0

Fabricius, K. E. (2005). Effects of terrestrial runoff on the ecology of corals and coral reefs: review and synthesis. Mar. Pollut. Bull. 50, 125-146. doi: 10.1016/j. marpolbul.2004.11.028

Ferrier-Pagès, C., Hoogenboom, M., and Houlbrèque, F. (2011). "The role of plankton in coral trophodynamics," in Coral Reefs: An Ecosystem in Transition, eds Z. Dubinsky and N. Stambler (Dordrecht: Springer), 215-229. doi: 10.1007/ 978-94-007-0114-4_15

Ferrier-Pagès, C., Leclercq, N., Jaubert, J., and Pelegrí, S. (2000). Enhancement of pico- and nanoplankton growth by coral exudates. Aquat. Microb. Ecol. 21, 203-209. doi: 10.3354/ame021203

Fitt, W. K., Gates, R. D., Hoegh-Guldberg, O., Bythell, J. C., Jatkar, A., Grottoli, A. G., et al. (2009). Response of two species of Indo-Pacific corals, Porites cylindrica and Stylophora pistillata, to short-term thermal stress: The host does matter in determining the tolerance of corals to bleaching. J. Exp. Mar. Biol. Ecol. 373, 102-110. doi: 10.1016/j.jembe.2009.03.011

Fitt, W. K., Mcfarland, F. K., Warner, M. E., and Chilcoat, G. C. (2000). Seasonal patterns of tissue biomass and densities of symbiotic dinoflagellates in reef corals and relation to coral bleaching. Limnol. Oceanogr. 45, 677-685. doi: 10.4319/lo.2000.45.3.0677
Flores, F., Hoogenboom, M. O., Smith, L. D., Cooper, T. F., David, A., Negri, A. P., et al. (2012). Chronic exposure of corals to fine sediments: lethal and sub-lethal impacts. PLoS One 7:e37795. doi: 10.1371/journal.pone.0037795

Glynn, P. W. (1996). Coral reef bleaching: facts, hypotheses and implications. Glob. Change Biol. 2, 495-509. doi: 10.1111/j.1365-2486.1996.tb00063.x

Grottoli, A. G., Rodrigues, L. J., and Juarez, C. (2004). Lipids and stable carbon isotopes in two species of Hawaiian corals, Porites compressa and Montipora verrucosa, following a bleaching event. Mar. Biol. 145, 621-631. doi: 10.1007/ s00227-004-1337-3

Guest, J. R., Tun, K., Low, J., Vergés, A., Marzinelli, E. M., Campbell, A. H., et al. (2016). 27 years of benthic and coral community dynamics on turbid, highly urbanised reefs off Singapore. Sci. Rep. 6, 36260. doi: 10.1038/srep36260

Gustafsson, M. S. M., Baird, M. E., and Ralph, P. J. (2013). The interchangeability of autotrophic and heterotrophic nitrogen sources in Scleractinian coral symbiotic relationships: a numerical study. Ecol. Model. 250, 183-194. doi: 10.1016/j. ecolmodel.2012.11.003

Harriott, V. J., Davis, D., and Banks, S. A. (1997). Recreational diving and its impact in marine protected areas in Eastern Australia. Ambio 26, 173-179. doi: $10.2307 / 4314577$

Hoegh-Guldberg, O., and Smith, G. J. (1989). Influence of the population density of zooxanthellae and supply of ammonium on the biomass and metabolic characteristics of the reef corals Seriatopora hystrix and Stylophora pistillata. Mar.Ecol.Prog.Ser. 57, 173-186. doi: 10.3354/meps057173

Howard, L. S. and Brown, B. E. (1984). Heavy metals and reef corals. Oceanogr. Mar. Biol. Ann. Rev. 22, 195-210.

Huang, J., Wang, F., Zhao, H., Xu, H., and Li, X. (2020). Reef benthic composition and coral communities at the Wuzhizhou Island in the south China sea: the impacts of anthropogenic disturbance. Estuar. Coast. Shelf Sci. 243, 106863. doi: 10.1016/j.ecss.2020.106863

Hughes, T. P., Huang, H., and Young, M. A. L. (2013). The wicked problem of china’s disappearing coral reefs. Conserv. Biol. 27, 261-269. doi: 10.1111/j.15231739.2012.01957.x

Jameson, S. C., Ammar, M. S. A., Saadalla, E., Mostafa, H. M., and Riegl, B. (1999). A coral damage index and its application to diving sites in the Egyptian Red Sea. Coral Reefs 18, 333-339. doi: 10.1007/s003380050208

Jokiel, P. L., and Coles, S. L. (1990). Response of hawaiian and other indopacific reef corals to elevated temperature. Coral Reefs 8, 155-162. doi: 10.1007/ BF00265006

Jones, R. J., and Yellowlees, D. (1997). Regulation and control of intracellular algae (= zooxanthellae) in hard corals. Philos. Trans. R. Soc. B Boil. Sci. 352, 457-468. doi: $10.1098 /$ rstb.1997.0033

Jones, R. J., Kildea, T., and Hoegh-Guldberg, O. (1999). PAM chlorophyll fluorometry: a new in situ technique for stress assessment in scleractinian corals, used to examine the effects of cyanide from cyanide fishing. Mar. Pollut. Bull. 38, 864-874. doi: 10.1016/S0025-326X(98)90160-6

Kaiser, H. F., and Rice, J. (1974). Little jiffy, mark IV. Educ. Psychol. Meas. 34, 111-117. doi: $10.1177 / 001316447403400115$

Krause, G. H., and Weis, E. (1991). Chlorophyll fluorescence and photosynthesis: the basics. Annu. Rev. Plant. Phys. 42, 313-349. doi: 10.1146/ANNUREV.PP.42. 060191.001525

Krieger, J. R., and Chadwick, N. E. (2013). Recreational diving impacts and the use of pre-dive briefings as a management strategy on Florida coral reefs. J. Coast. Conserv. 17, 179-189. doi: 10.1007/s11852-012-0229-9

Lamb, J. B., True, J. D., Piromvaragorn, S., and Willis, B. L. (2014). SCUBA diving damage and intensity of tourist activities increases coral disease prevalence. Biol. Conserv. 178, 88-96. doi: 10.1016/j.biocon.2014.0 6.027

Lei, X. M., Huang, H., Wang, H. J., Li, X. B., and Lian, J. S. (2008). A preliminary study of effect of elevated temperature stress on three reef corals and their zooxanthellae. J. Trop. Oceanogr. Chin. 27, 55-59.

Levas, S., Schoepf, V., Warner, M. E., Aschaffenburg, M., Baumann, J., and Grottoli, A. G. (2018). Long-term recovery of Caribbean corals from bleaching. J. Exp. Mar. Biol. Ecol. 506, 124-134. doi: 10.1016/j.jembe.2018.06.003

Li, X. B., Huang, H., Lian, J. S., Yang, J. H., and Huang, L. M. (2012). Coral community changes in response to a high sedimentation event: a case study in southern Hainan Island. Chinese Sci. Bull. 58, 1028-1037. doi: 10.1007/s11434012-5601-5 
Li, X. B., Huang, H., Qu, F. U., Dong, Z. J., and Huang, L. M. (2006). Effects of temperature on bleaching of Acropora nasuta. J. Trop. Oceanogr. Chin. 25, 58-62.

Linares, C., Pratchett, M. S., and Coker, M. S. (2011). Recolonisation of Acropora hyacinthus following climate-induced coral bleaching on the Great Barrier Reef. Mar. Ecol. Prog. Ser. 438, 97-104. doi: 10.3354/meps09272

Long, S. P., Humphries, S., and Falkowski, P. G. (1994). Photoinhibition of photosynthesis in nature. Annu. Rev. Plant Physiol. Plant mol. Biol. 45, 633-662. doi: 10.1146/ANNUREV.PP.45.060194.003221

Mastny, L. (2001). A worldwatch addendum on coral reef. World Watch 14, 20-21.

Mills, M. M., and Sebens, K. P. (2004). Ingestion and assimilation of nitrogen from benthic sediments by three species of coral. Mar. Biol. 145, 1097-1106. doi: 10.1007/s00227-004-1398-3

Mills, M. M., Lipschultz, F., and Sebens, K. P. (2004). Particulate matter ingestion and associated nitrogen uptake by four species of scleractinian corals. Coral Reefs 23, 311-323. doi: 10.1007/s00338-004-0380-3

Muscatine, L., Falkowski, P. G., Dubinsky, Z., Cook, P. A., and McCloskey, L. R. (1989). The effect of external nutrient resources on the population dynamics of zooxanthellae in a reef coral. Proc. R. Soc. Lond. B 236, 311-324. doi: 10.1098/ rspb.1989.0025

Nystrm, M., Folke, C., and Moberg, F. (2000). Coral reef disturbance and resilience in a human-dominated environment. Trends Ecol. Evol. 15, 413-417. doi: 10. 1016/S0169-5347(00)01948-0

Ong, T. F., and Musa, G. (2011). An examination of recreational divers' underwater behaviour by attitude-behaviour theories. Curr. Issues Tour. 14, 779-795. doi: 10.1080/13683500.2010.545370

Palomar, M. J. S., Yap, H. T., and Gomez, E. D. (2009). Coral transplant survival over 3 years under different environmental conditions at the hundred islands, philippines. Philipp. Agric. Sci. 92, 143-152. doi: 10.1002/jsfa.3621

Perry, C. T., Smithers, S. G., and Johnson, K. G. (2009). Long-term coral community records from lugger shoal on the terrigenous inner-shelf of the central great barrier reef, Australia. Coral Reefs 28, 941-948. doi: 10.1007/ s00338-009-0528-2

Precoda, K., Hardt, M. J., Baird, A. H., and Madin, J. S. (2020). Tissue biomass trades off with growth but not reproduction in corals. Coral Reefs 39, 10271037. doi: 10.1007/s00338-020-01925-7

Reopanichkul, P., Schlacher, T. A., Carter, R. W., and Worachananant, S. (2009). Sewage impacts coral reefs at multiple levels of ecological organization. Mar. Pollut. Bull. 58, 1356-1362. doi: 10.1016/j.marpolbul.2009.04.024

Riegl, B., and Branch, G. M. (1995). Effects of sediment on the energy budgets of four scleractinian (Bourne 1900) and five alcyonacean (Lamouroux 1816) corals. J. Exp. Mar. Biol. Ecol. 186, 259-275. doi: 10.1016/0022-0981(94)00 164-9

Rogers, C. S. (1979). The effect of shading on coral reef structure and function. J. Exp. Mar. Biol. Ecol. 41, 269-288. doi: 10.1016/0022-0981(79)90136-9

Rogers, C. S. (1990). Responses of coral reefs and reef organisms to sedimentation. Mar. Ecol. Prog. Ser. 62, 185-202. doi: 10.3354/meps062185

Rouphael, A., and Inglis, G. (2002). Increased spatial and temporal variability in coral damage caused by recreational scuba diving. Ecol. Appl. 12, 427-440. doi: $10.2307 / 3060953$

Shi, T., Niu, G., Kvitt, H., Zheng, X., Qin, Q., Sun, D., et al. (2020). Untangling ITS2 genotypes of algal symbionts in zooxanthellate corals. Mol. Ecol. Resour. 21, 137-152. doi: 10.1111/1755-0998.13250

Smith, P. K., Krohn, R. I., and Hermanson, G. T. (1985). Measurement of protein using bicinchoninic acid. Anal. Biochem. 163, 76-85. doi: 10.1016/00032697(85)90442-7

Solomon, S. L., Grottoli, A. G., Warner, M. E., Levas, S., and Muoz-Garcia, A. (2020). Correction to: Lipid class composition of annually bleached Caribbean corals. Mar. Biol. 167, 27. doi: 10.1007/s00227-020-3652-8
Stafford-Smith, M. G. (1993). Sediment-rejection efficiency of 22 species of Australian scleractinian corals. Mar. Biol. 115, 229-243. doi: 10.1007/ BF00346340

Stafford-Smith, M., and Ormond, R. (1992). Sediment-rejection mechanisms of 42 species of Australian scleractinian corals. Mar. Freshw. Res. 43, 683-705. doi: 10.1071/MF9920683

Seebauer, J. (2001). Zoology of Porites cylindrica: potential for use in reefrehabilitation transplantation efforts. SUNY Geneseo. J. Sci. Math. 2, 26-34.

Sudara, S., and Yeemin, T. (1997). "Status of coral reefs in Thailand," in Sea Grant College Program, School of Ocean and Earth Science and Technology, eds R. W. Grigg and C. Birkeland (Honolulu, HI: University of Hawaii), 135-144.

Tong, H., Cai, L., Zhou, G., Yuan, T., Zhang, W., Tian, R., et al. (2017). Temperature shapes coral-algal symbiosis in the South China Sea. Sci. Rep. 7:40118. doi: 10.1038/srep40118

Uyarra, M. C., and $\mathrm{Co}^{\wedge} \mathrm{te}^{\prime}$, I. M. (2007). The quest for cryptic creatures: Impacts of species-focused recreational diving on corals. Biol. Conserv. 136, 77-84. doi: 10.1016/j.biocon.2006.11.006

Weber, M., De Beer, D., Lott, C., Polerecky, L., and Fabricius, K. E. (2012). Mechanisms of damage to corals exposed to sedimentation. Proc. Natl. Acad. Sci. U.S.A. 109, E1558-E1567. doi: 10.1073/pnas.1100715109

Weber, M., Lott, C., and Fabricius, K. E. (2006). Sedimentation stress in a scleractinian coral exposed to terrestrial and Mar. sediments with contrasting physical, organic and geochemical properties. J. Exp. Mar. Biol. Ecol. 336, 18-32. doi: 10.1016/j.jembe.2006.04.007

Wielgus, J., Chadwick-Furman, N. E., and Dubinsky, Z. (2004). Coral cover and partial mortality on anthropogenically impacted coral reefs at Eilat, northern Red Sea. Mar. Pollut. Bull. 48, 248-253. doi: 10.1016/j.marpolbul.2003.08.008

Wild, C., Rasheed, M., Werner, U., Franke, U., and Huettel, M. (2004). Degradation and mineralization of coral mucus in reef environments. Mar. Ecol. Prog. Ser. 267, 159-171. doi: 10.3354/meps267159

Xu, H., Feng, B., Xie, M., Ren, Y., and Li, X. (2020). Physiological characteristics and environment adaptability of reef-building corals at the wuzhizhou island of South China Sea. Front. Physiol. 11:390. doi: 10.3389/fphys.2020.00390

Zakai, D., and Chadwick-Furman, N. E. (2002). Impacts of intensive recreational diving on reef corals at Eilat, northern Red Sea. Biol. Conserv. 105, 179-187. doi: 10.1016/S0006-3207(01)00181-1

Zhu, B. H., Wang, G. C., and Huang, B. (2004). Effects of temperature, hypoxia, ammonia and nitrate on the bleaching among three coral species. Chin. Sci. Bull. 49, 1923-1928. doi: 10.1360/04wc0195

Conflict of Interest: The authors declare that the research was conducted in the absence of any commercial or financial relationships that could be construed as a potential conflict of interest.

Publisher's Note: All claims expressed in this article are solely those of the authors and do not necessarily represent those of their affiliated organizations, or those of the publisher, the editors and the reviewers. Any product that may be evaluated in this article, or claim that may be made by its manufacturer, is not guaranteed or endorsed by the publisher.

Copyright (c) 2021 Zhang, Huang, Li, Song, Xia, Ren, Wang and Li. This is an open-access article distributed under the terms of the Creative Commons Attribution License (CC BY). The use, distribution or reproduction in other forums is permitted, provided the original author(s) and the copyright owner(s) are credited and that the original publication in this journal is cited, in accordance with accepted academic practice. No use, distribution or reproduction is permitted which does not comply with these terms. 